Technical Note

\title{
Spatial Disaggregation of Latent Heat Flux Using Contextual Models over India
}

\author{
Rajasekaran Eswar ${ }^{1}$ (D), Muddu Sekhar ${ }^{1,2, *}$, Bimal K. Bhattacharya ${ }^{3}$ and \\ Soumya Bandyopadhyay 4 \\ 1 Department of Civil Engineering, Indian Institute of Science, Bangalore 560012, India; eswar1204@gmail.com \\ 2 Interdisciplinary Centre for Water Research, Indian Institute of Science, Bangalore 560012, India \\ 3 Space Applications Centre, Indian Space Research Organisation, Ahmedabad 380015, India; \\ bkbhattacharya@sac.isro.gov.in \\ 4 Indian Space Research Organisation, Bangalore 560231, India; bandyo@isro.gov.in \\ * Correspondence: sekhar.muddu@gmail.com; Tel.: +91-80-2293-2245
}

Received: 20 July 2017; Accepted: 11 September 2017; Published: 13 September 2017

\begin{abstract}
Estimation of latent heat flux at the agricultural field scale is required for proper water management. The current generation thermal sensors except Landsat- 8 provide data on the order of $1000 \mathrm{~m}$. The aim of this study is to test three approaches based on contextual models using only remote sensing datasets for the disaggregation of latent heat flux over India. The first two approaches are, respectively, based on the estimation of the evaporative fraction (EF) and solar radiation ratio at coarser resolution and disaggregating them to yield the latent heat flux at a finer resolution. The third approach is based on disaggregation of the thermal data and estimating a finer resolution latent heat flux. The three approaches were tested using MODIS datasets and the validation was done using the Bowen Ratio energy balance observations at five sites across India. From the validation, it was observed that the first two approaches performed similarly and better than the third approach at all five sites. The third approach, based on the disaggregation of the thermal data, yielded larger errors. In addition to better performance, the second approach based on the disaggregation of solar radiation ratio was simpler and required lesser data processing than the other approaches. In addition, the first two approaches captured the spatial pattern of latent heat flux without introducing any artefacts in the final output.
\end{abstract}

Keywords: Latent Heat Flux; Evaporative Fraction; MODIS; triangle model; DEFrac

\section{Introduction}

Latent heat flux ( $\lambda E, \mathrm{~W} \mathrm{~m}^{-2}$ or evapotranspiration, $\mathrm{ET}$, expressed in $\left.\mathrm{mm}\right)$ is a widely required input for agricultural water management. Proper crop water monitoring and irrigation scheduling require the estimation of $\lambda E$ at the field scale and at regular time intervals. This need for repeated monitoring of $\lambda E$ over a large number of agricultural fields in a region have led to the development of different remote sensing (RS)-based models based on the surface energy balance equation (e.g., [1,2]). Furthermore, the RS-based models have been operationalized (e.g., [3]) over some regions of the globe to estimate the field scale $\lambda E$ using high spatial resolution data $(\sim 100 \mathrm{~m})$ from satellites, like Landsat-5, Landsat-7, and Landsat-8.

The primary input to the surface energy balance models is the land surface temperature $\left(T_{\text {Rad }}\right.$, K) observed by thermal infrared (TIR) sensors. Among the currently-operational satellites, most of the TIR sensors, except the one aboard Landsat-8, have spatial resolution on the order of $1000 \mathrm{~m}$ or more. Landsat- 8 has a nominal revisit cycle of 16 days and hence, the number of high-resolution $T_{\text {Rad }}$ images available from the single Landsat satellite is not sufficient for periodic monitoring of land surface fluxes $\lambda E$ [4]. Due to this reason, sensors with frequent revisits, but coarse spatial resolution, 
like MODIS, are often used for repeated estimation of $\lambda E$. The coarse spatial resolution of TIR data from sensors, such as MODIS, necessitated the development of models to disaggregate $T_{\text {Rad }}[5-8]$ and use the disaggregated $T_{\text {Rad }}$ for estimating $\lambda E$ with improved spatial resolution. In addition to this, studies have also been carried out to disaggregate evaporative fraction (EF, defined as the ratio of latent heat flux to the sum of sensible and latent heat fluxes) [9] or ET itself [10].

The need for such spatial disaggregation models is further increased over India, where agricultural fields with dimensions of one or two hundred of meters are more common. A single MODIS pixel at $1000 \mathrm{~m}$ resolution may include several tens of plots and, hence, it becomes highly difficult to monitor $\lambda E$ at the field scale. However, multiple studies have been carried out for the estimation of $\lambda E$ over India [11-13], and they all analyzed data at a coarse spatial resolution $(\geq 1000 \mathrm{~m})$. A previous study [8] tested the utility of disaggregated $T_{\mathrm{Rad}}$ for the estimation of fine resolution $\lambda E$ over an area in south India, however, the disaggregated $\lambda E$ was not validated due to the lack of ground measurements. Another study [9] developed a model called disaggregation of evaporative fraction (DEFrac), which takes in coarse-resolution EF and disaggregates it to a finer resolution using the EF-NDVI relationship. The DEFrac model, though found to work with good accuracy over Indian sites, the disaggregated EF should be converted into $\lambda E$ by multiplying with net available energy at the surface $\left(\left(R_{\mathrm{n}}-G\right), R_{\mathrm{n}}\right.$ is the net radiation and $G$ is the soil heat flux, $\mathrm{W} \mathrm{m}^{-2}$ ) for use in various applications. The estimation of $\left(R_{\mathrm{n}}-G\right)$ at fine spatial resolution require several other inputs that are either available at the target resolution (e.g., NDVI, surface albedo etc.) or that can be disaggregated from coarser resolution data (e.g., $\left.T_{\text {Rad }}\right)$. The complexities involved in estimating disaggregated $\left(R_{\mathrm{n}}-G\right)$ can be avoided if EF can be replaced with some other ratio, which requires minimal data to be converted into $\lambda E$. Previous studies, e.g., [14-16], suggested that the global solar radiation ratio $\left(R_{\mathrm{g}}\right.$, defined as the ratio of latent heat flux to the incoming global solar radiation) can be utilized for the estimation of $\lambda E$. The only variable required to convert $R_{\mathrm{g}}$ into $\lambda E$ is the global incoming solar radiation at the surface $\left(R_{\mathrm{sd}}\right)$ which can be observed or modelled relatively easier than $\left(R_{\mathrm{n}}-G\right)$. To the best knowledge of the authors, there are hardly any studies available in the literature that compare different approaches for estimating $\lambda E$ at finer resolutions over Indian ecosystems. Based on these, the objectives of this study are formulated as follows:

1. Disaggregate satellite estimated EF and $R_{\mathrm{g}}$ from $1000 \mathrm{~m}$ into $250 \mathrm{~m}$ and subsequently convert the disaggregated EF and $R_{\mathrm{g}}$ into daytime integrated latent heat flux $\left(\lambda E_{\text {day }}\right)$ at $250 \mathrm{~m}$ resolution; and

2. Compare the $\lambda E_{\text {day }}$ estimated using the first two approaches with that estimated from the disaggregation of $T_{\text {Rad }}$ using the DisTrad thermal sharpening model $[9,17]$.

\section{Study Sites and Datasets}

\subsection{Study Sites and In Situ Data}

The three disaggregation approaches were tested at five sites across India. Each of the five sites is equipped with a Bowen Ratio energy balance (BREB) micrometeorological tower and the location of all the five sites are indicated in Figure 1. Site 1 is in a young pine forest amidst an urban town in Northern India. All other sites are in farmlands with cropping predominantly carried out in two seasons known as kharif (June-September, summer monsoon season) and rabi (November-January, winter cropping season). Additional details about the five tower sites can be obtained from [13,17]. For the proper determination of the various context spaces (e.g., $\left.T_{\text {Rad }}-\mathrm{NDVI}\right)$ for the models used in this study, spatial grids of approximately $100 \mathrm{~km} \times 100 \mathrm{~km}$ were delineated enclosing the tower sites.

Each of the BREB towers are $10 \mathrm{~m}$ in height. Air temperature and relative humidity are measured at $2 \mathrm{~m}, 4 \mathrm{~m}$, and $6 \mathrm{~m}$ above ground level. Wind speed and wind direction are measured at $2.5 \mathrm{~m}, 5 \mathrm{~m}$, and $10 \mathrm{~m}$ heights. The different components of surface radiation are measured using a Kipp and Zonen (Delft, The Netherlands) four-component net radiometer ( $3 \mathrm{~m}$ above the ground). Two soil heat flux plates are installed at $0.15 \mathrm{~m}$ and $0.3 \mathrm{~m}$ below the surface and atmospheric pressure is measured at $2 \mathrm{~m}$ above ground level using a transducer. Apart from these, the tower has a tipping bucket rain gauge 
(at $1 \mathrm{~m}$ above ground) for measuring rainfall and a shaded pyranometer (at $4 \mathrm{~m}$ above ground) for diffuse radiation measurements. Three soil thermometers and tensiometers to measure, respectively, the soil temperature and the soil suction head are installed at $0.05 \mathrm{~m}, 0.15, \mathrm{~m}$ and $0.3 \mathrm{~m}$ below the surface. All the measured variables are sampled every five minutes and the five-minute samples are averaged over half-hourly intervals. The half-hourly averages are stored in a data logger and transmitted to the server of the Space Applications Centre located at Ahmedabad in India.

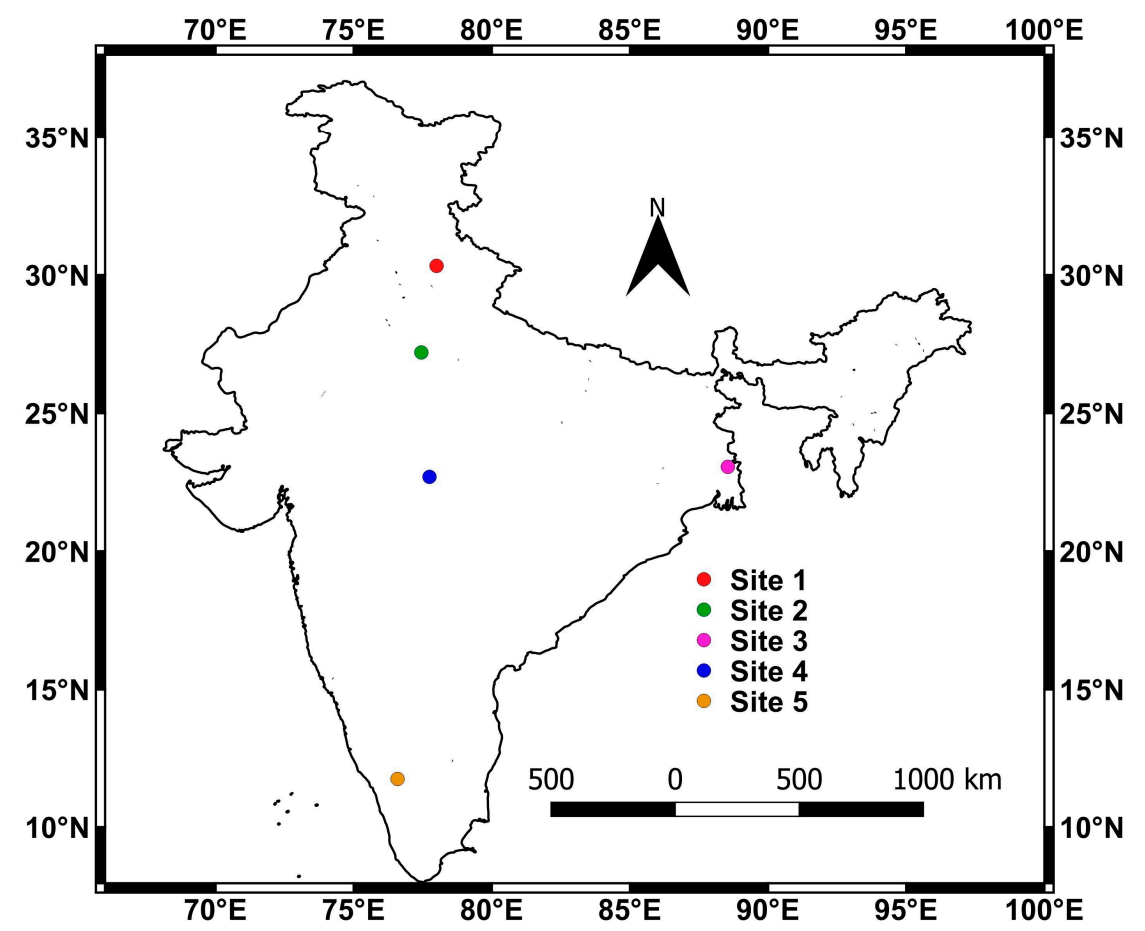

Figure 1. Location of the five BREB tower sites.

\subsection{Satellite Data}

The satellite data required for the study were obtained from the MODIS sensor onboard the Terra and Aqua satellites. All of the data products used are daily datasets acquired during the daytime overpass of the satellites. $T_{\text {Rad }}$, Land surface emissivity $\left(\varepsilon_{\mathrm{s}}\right)$ and satellite view time were obtained from the MOD11A1/MYD11A1 dataset at $1000 \mathrm{~m}$ spatial resolution. The seven-band surface reflectance at $500 \mathrm{~m}$ and solar zenith angle at satellite view time $(1000 \mathrm{~m})$ were obtained from the MOD09GA/MYD09GA product. In addition to this, for disaggregation purposes, the surface reflectance at red and near-infrared bands at $250 \mathrm{~m}$ were also obtained from the MOD09GQ/MYD09GQ data product. Furthermore, air temperature $\left(T_{\mathrm{a}}\right)$ data was obtained from the MODIS atmospheric profile level 2 product at a $5000 \mathrm{~m}$ pixel resolution. A total of 248 datasets were downloaded from the two satellites for all five sites together $(59,54,35,42$, and 58 datasets for sites $1-5$, respectively).

\section{Methodology}

\subsection{Brief Overview of the Disaggregation Approaches}

In this study, $\lambda E_{\text {day }}$ was estimated either as a product of $E F$ and $\left(R_{n}-G\right)_{\text {day }}$ or as a product of $R_{\mathrm{g}}$ and $\left(\mathrm{R}_{\mathrm{sd}}\right)_{\text {day }}$ (the subscript 'day' refers to the daytime integrated value). To disaggregate $\lambda \mathrm{E}_{\text {day }}$ from MODIS thermal data at $1000 \mathrm{~m}$ to $250 \mathrm{~m}$ spatial resolution, three different approaches were adopted. In Approach 1, EF was estimated, first, at $1000 \mathrm{~m}$ resolution and disaggregated to $250 \mathrm{~m}$ using the DEFrac model [9]. Simultaneously, the MODIS $\mathrm{T}_{\text {Rad }}$ data was disaggregated from $1000 \mathrm{~m}$ to $250 \mathrm{~m}$ using the DisTrad thermal sharpening model [17] and subsequently used in the estimation 
of $\left(R_{n}-G\right)$ day at $250 \mathrm{~m}$ resolution. These disaggregated EF and $\left(R_{n}-G\right)$ day were multiplied to get $\lambda E_{\text {day }}$ at $250 \mathrm{~m}$ resolution. Approach 3 was similar to Approach 1, in the estimation of $\lambda E_{\text {day }}$; however, the $\mathrm{EF}$ was estimated directly at $250 \mathrm{~m}$ using the $\mathrm{T}_{\mathrm{Rad}}$ disaggregated to $250 \mathrm{~m}$. In Approach 2, the $\mathrm{EF}$ estimated at $1000 \mathrm{~m}$ was converted into $R_{\mathrm{g}}$ and this was disaggregated to $250 \mathrm{~m}$ using the DiSoRa disaggregation model (Section 3.3). This disaggregated $R_{\mathrm{g}}$ was multiplied with $\left(\mathrm{R}_{\mathrm{sd}}\right)_{\text {day }}$ to get $\lambda \mathrm{E}_{\text {day }}$ at $250 \mathrm{~m}$. The schematic of the three approaches are presented in Figure 2 and the various models used are explained in the following sections. All the models used in this work were forced with inputs that are obtainable only from RS datasets without any ground measurements. In Figure 2, FVC and NDWI indicate, respectively, the fraction vegetation cover and normalized difference water index (sometimes referred as normalized difference moisture index), which was used in the disaggregation of $\mathrm{T}_{\mathrm{Rad}}$ [17].

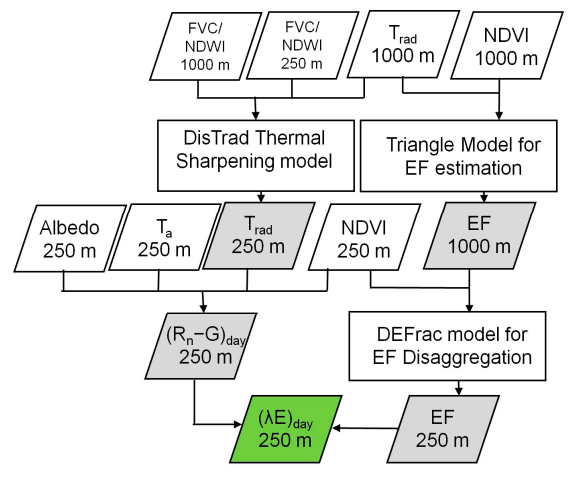

Approach 1

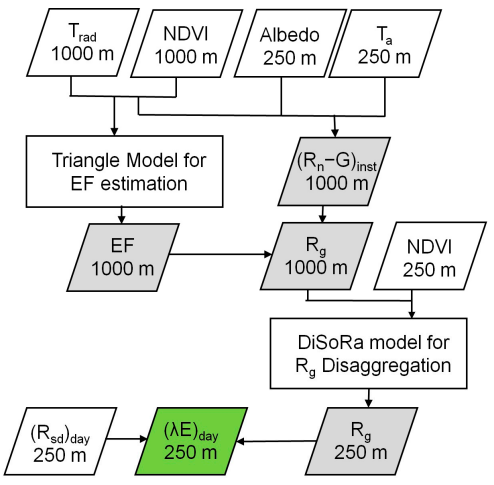

Approach 2

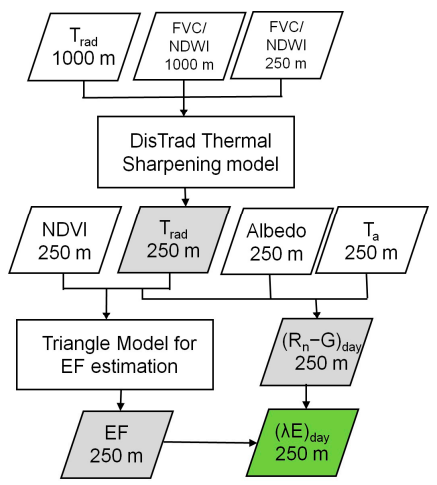

Approach 3

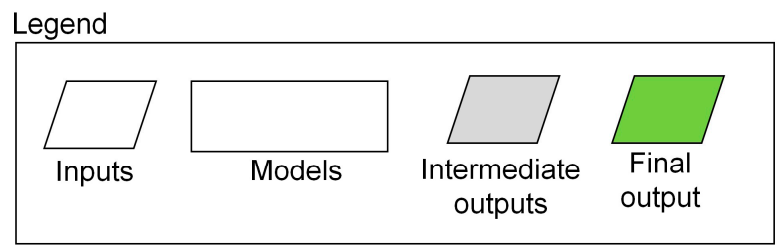

Figure 2. Flowchart indicating the steps involved in estimating $\lambda E_{\text {day }}$ at $250 \mathrm{~m}$ using the three approaches.

\subsection{Estimation of EF and $R_{g}$ from Satellite Data}

The EF was estimated using the triangle model [18], which is based on the $T_{\text {Rad }}$-NDVI relationship. Several studies have successfully utilized the triangle model for the estimation of EF or $\lambda E$ (e.g., [19-24]) at various spatial scales. Over India, the triangle model for EF estimation was tested by $[9,13]$ and a detailed review of the various studies that utilized the $T_{\text {Rad }}$-NDVI relationship was provided by [25]. In this study, for the triangle model, the dry edge was determined using the automated algorithm proposed by [21] and the wet edge was determined as the minimum value of $T_{\mathrm{Rad}}$ at maximum NDVI [18] with NDVI being calculated from the first two bands of the MODIS surface reflectance data product. The $T_{\text {Rad }}$-NDVI context space was determined using all the MODIS pixels (at both $1000 \mathrm{~m}$ and $250 \mathrm{~m}$ resolutions) with in the spatial grids enclosing the tower sites. The EF from the triangle model was converted into $R_{\mathrm{g}}$ as given by:

$$
R_{\mathrm{g}}=\frac{\lambda E_{\text {inst }}}{\left(R_{\mathrm{sd}}\right)_{\text {inst }}}=\frac{E F \times\left(R_{\mathrm{n}}-G\right)_{\text {inst }}}{\left(R_{\mathrm{sd}}\right)_{\text {inst }}}
$$

where the subscript 'inst' indicates the estimation of energy terms at the instant of satellite overpass. $\left(R_{\mathrm{n}}-G\right)_{\text {inst }}$ was estimated as [11]:

$$
\left(R_{\mathrm{n}}\right)_{\text {inst }}=\left([1-\alpha] R_{\mathrm{sd}}+\varepsilon_{\mathrm{s}} \varepsilon_{\mathrm{a}} \sigma\left(T_{\mathrm{a}}\right)^{4}-\varepsilon_{\mathrm{s}} \sigma\left(T_{\text {Rad }}\right)^{4}\right)_{\text {inst }}
$$




$$
G_{\text {inst }}=\left(R_{\mathrm{n}}\right)_{\text {inst }}\left[\left(T_{\text {Rad }} / \alpha\right) \times\left(0.0032 \alpha+0.0062 \alpha^{2}\right) \times\left(1+0.978 \mathrm{NDVI}^{4}\right)\right]
$$

where $\alpha$ is the surface albedo, $\varepsilon_{\mathrm{s}}$ and $\varepsilon_{\mathrm{a}}$ are surface and air emissivity, respectively, $\sigma$ is the Stefan-Boltzmann constant $\left(5.67 \times 10^{-8} \mathrm{~W} \mathrm{~m}^{-2} \mathrm{~K}^{-1}\right)$, and $T_{\mathrm{a}}$ and $T_{\text {Rad }}$ are the air and land surface temperature $(\mathrm{K})$, respectively. $\alpha$ was estimated from the MODIS seven-band surface reflectance data following [26] and the $\varepsilon_{\mathrm{s}}$ was estimated from the emissivity of bands 31 and 32 in MODIS following [27]. In Equations (2) and (3), $\left(R_{\mathrm{sd}}\right)_{\text {inst }}$ [11] and $\varepsilon_{\mathrm{a}}$ [28] were estimated as:

$$
\begin{gathered}
\left(R_{\mathrm{sd}}\right)_{\text {inst }}=a S_{0} f(\cos \theta)^{b} \\
\varepsilon_{a}=9.2 T_{a}^{2} \times 10^{-6}
\end{gathered}
$$

where $a(=0.75)$ and $b(=1.28)$ are empirical coefficients, $S_{0}$ is the solar constant $\left(=1367 \mathrm{~W} \mathrm{~m}^{-2}\right), f$ is the Sun-Earth distance correction factor in astronomical units, and $\theta$ is the solar zenith angle (radians). The detailed explanation of the models used to estimate EF and $\left(R_{n}-G\right)$ is provided in [13].

\subsection{Disaggregation of $R_{g}$ and $E F$}

For the disaggregation of $R_{\mathrm{g}}$, a model called DiSoRa (DIsaggregation of SOlar radiation RAtio) is proposed based on the observed inverse triangular relationship between $R_{\mathrm{g}}$ and NDVI. The DiSoRa is a contextual model which utilizes the variation of $R_{\mathrm{g}}$ with different values of NDVI in a given satellite scene. The schematic of the model is given in Figure 3.

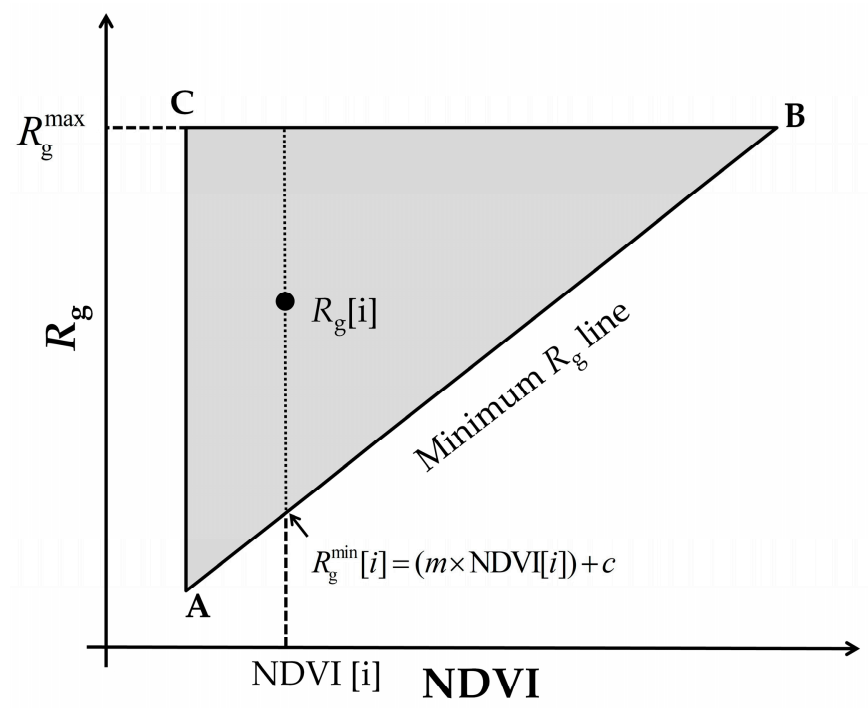

Figure 3. Schematic of the DiSoRa model.

In Figure 3, the minimum value of $R_{\mathrm{g}}$ for a given value of NDVI increases with increasing NDVI (indicated by hypotenuse $\mathrm{AB}$ ). The scatter above the minimum $R_{\mathrm{g}}$ line is due to soil moisture variation and the effect of soil moisture is higher (indicated by larger scatter) under lower canopy cover and it decreases with the increase in NDVI (indicating an increase in canopy cover). This kind of inverse relationship between EF and NDVI was observed by [11] and was utilized in the development of the DEFrac model for the disaggregation of EF [9]. The DiSoRa model is a direct extension of the EF-NDVI relationship to the $R_{\mathrm{g}}$-NDVI relationship.

In the application of the DiSoRa model, it is assumed that, for a given satellite scene, the minimum and maximum bounds (AB and BC, respectively, in Figure 3) can be established between $R_{\mathrm{g}}$ and NDVI, and these bounds are scale independent. For the MODIS scale data at $1000 \mathrm{~m}$ resolution, a linear 
regression was performed between minimum vales of $R_{\mathrm{g}}$ and NDVI to determine the slope $(m)$ and intercept (c) as given below:

$$
R_{\mathrm{g}, 1000}^{\min }=\left(m \times N D V I_{1000}\right)+c
$$

The regression was carried out in an automated way following the edge detection algorithm in [21] with suitable modifications. Then, for any given pixel $i$ in the $1000 \mathrm{~m}$ image, the fraction $(d)$ by which the $R_{\mathrm{g}}$ of that pixel $\left(R_{\mathrm{g}, 1000}\right)$ deviates from the minimum bound was estimated as:

$$
d[i]=\frac{R_{\mathrm{g}, 1000}[i]-R_{\mathrm{g}, 1000}^{\min }[i]}{R_{\mathrm{g}, 1000}^{\max }-R_{\mathrm{g}, 1000}^{\min }[i]}
$$

where the minimum $R_{\mathrm{g}}$ was estimated using NDVI of that pixel in Equation (6) and $R_{\mathrm{g}, 1000}^{\max }$ is the maximum value of $R_{\mathrm{g}}$ found in the scene. Then, for any subpixel $j$ at $250 \mathrm{~m}$ resolution with in the given $1000 \mathrm{~m}$ pixel $i\left(j\right.$ will vary between 1 and 16), the disaggregated $R_{\mathrm{g}}$ at $250 \mathrm{~m}\left(\hat{R}_{\mathrm{g}, 250}\right)$ resolution was estimated as:

$$
\hat{R}_{\mathrm{g}, 250}[j]=R_{\mathrm{g}, 250}^{\min }[j]+\left\{d[i] \times\left(R_{\mathrm{g}, 1000}^{\max }-R_{\mathrm{g}, 250}^{\min }[j]\right)\right\}
$$

where, $R_{\mathrm{g}, 250}^{\min }[j]$ was estimated using the NDVI at $250 \mathrm{~m}$ resolution in Equation (6). From Equation (8), it can be observed that the fraction $d$ is kept constant for all the 16 subpixels within a $1000 \mathrm{~m}$ pixel. Further, it should also be noted that, though the fraction $d$ is kept constant for all the subpixels, the actual soil moisture term (part of equation within the curly braces \{\} ) will vary based on the NDVI of that subpixel $j$. For a pixel with higher value of NDVI, the added soil moisture control term will be less and vice versa. Since the disaggregation model is contextual in nature, for the successful implementation of the model, the satellite scene should have a wide range in NDVI and pixels evaporating at potential and minimal rates should be found within the scene. The NDVI required at $250 \mathrm{~m}$ was estimated from the MODIS two-band surface reflectance product available at $250 \mathrm{~m}$. For the disaggregation of EF to $250 \mathrm{~m}$, the DEFrac model was used by replacing $R_{\mathrm{g}}$ with $\mathrm{EF}$ in Equations (6)-(8). Both the $R_{\mathrm{g}}$-NDVI context space and EF-NDVI context space were established over the same spatial grids $(\sim 100 \mathrm{~km} \times 100 \mathrm{~km})$ which are used in the triangle model enclosing the tower site.

\subsection{Disaggregation of $T_{\text {Rad }}$}

For the estimation of $\left(R_{\mathrm{n}}-G\right)$ at $250 \mathrm{~m}$ (for Approaches 1 and 3) and for the estimation of EF at $250 \mathrm{~m}$ (for Approach 3), it was necessary to disaggregate the MODIS $T_{\text {Rad }}$ from $1000 \mathrm{~m}$ to $250 \mathrm{~m}$. For this purpose, the DisTrad model [5,6] was utilized. The DisTrad thermal sharpening model is based on the relationship between $T_{\text {Rad }}$ and a vegetation index. Originally, NDVI and FVC were proposed and used in the model, however, a recent study [17] showed that the choice of vegetation index in the DisTrad model depends on the dryness/wetness of the study area. Only during wetter conditions, NDVI/FVC yielded more accurate results in the DisTrad model. For drier conditions, NDWI was found to be the better-performing vegetation index. In this study, too, the choice of index was decided by the temperature vegetation dryness index (TVDI), as shown in [17]. For the sake of clarity, the DisTrad thermal sharpening model is not explained here and the readers are directed to refer to [17] for the complete information about the DisTrad model and its application.

\subsection{Estimation of $\lambda E_{\text {day }}$ at $250 m$ Resolution}

After the estimation of $\mathrm{EF}$ and $R_{\mathrm{g}}$ at $250 \mathrm{~m}$ using the three approaches, $\lambda E_{\text {day }}$ was estimated from them at $250 \mathrm{~m}$ resolution. The EF was converted into $\lambda E_{\text {day }}$ using (Approaches 1 and 3):

$$
\lambda E_{\text {day, } 250}=E F_{250} \times\left(R_{\mathrm{n}}-G\right)_{\text {day }, 250}
$$


Here the subscripts '250'and 'day' indicate the target resolution of $250 \mathrm{~m}$ and daytime integrated values of the energy fluxes respectively. The $\left(R_{\mathrm{n}}-G\right)_{\text {inst }}$ estimated from Equations (2) and (3) was temporally extrapolated to daytime using a simple sinusoidal extrapolation equation [29]:

$$
\left(R_{\mathrm{n}}-G\right)_{\text {day }}=\frac{2\left(R_{\mathrm{n}}-G\right)_{\text {inst }}}{\pi \sin \left[\pi\left(\frac{t_{\text {pass }}-t_{\text {rise }}}{t_{\text {set }}-t_{\text {pass }}}\right)\right]}
$$

where $t_{\text {pass }}, t_{\text {rise, }}$ and $t_{\text {set }}$ are, respectively, the time of the satellite overpass, sunrise, and sunset. The sunrise and sunset times were estimated based on standard equations using the latitude and longitude of the satellite pixel. For the estimation of $\left(R_{\mathrm{n}}-G\right)_{\text {inst }}$ at $250 \mathrm{~m}$ resolution, all the necessary inputs were converted into $250 \mathrm{~m}$ as given in Table 1 . In Approach $2, \lambda E_{\text {day }}$ at $250 \mathrm{~m}$ was estimated from the disaggregated $R_{\mathrm{g}}$. The $\left(\mathrm{R}_{\mathrm{sd}}\right)_{\text {day }}$ was modelled using Equation (10) after substituting $\left(R_{\mathrm{n}}-G\right)_{\text {inst }}$ with $\left(R_{\mathrm{sd}}\right)_{\text {inst }}($ Equation (4)).

Table 1. Getting the input variables for estimating $\left(R_{\mathrm{n}}-G\right)_{\text {day }}$ at $250 \mathrm{~m}$ resolution.

\begin{tabular}{|c|c|c|}
\hline Variables & Data Source with Available Resolution & $\begin{array}{c}\text { Method Adopted to Get the Variable at } 250 \mathrm{~m} \\
\text { Resolution }\end{array}$ \\
\hline Solar zenith angle $(\theta)$ & $\begin{array}{l}\text { Available from MODIS 7-band surface } \\
\text { reflectance product at } 1000 \mathrm{~m} \text { resolution. }\end{array}$ & $\begin{array}{l}\text { Assumed the same value for all the } 250 \mathrm{~m} \text { pixels } \\
\text { within a single } 1000 \mathrm{~m} \text { pixel. }\end{array}$ \\
\hline Surface albedo $(\alpha)$ & $\begin{array}{l}\text { Estimated from MODIS 7-band surface } \\
\text { reflectance product at } 500 \mathrm{~m} \text { resolution [28]. }\end{array}$ & Bilinear interpolation to $250 \mathrm{~m}$ \\
\hline NDVI & $\begin{array}{l}\text { Estimated from MODIS 7-band / 2-band surface } \\
\text { reflectance product at } 500 \mathrm{~m} \text { and } 250 \mathrm{~m} \text {, } \\
\text { respectively. }\end{array}$ & Available from MODIS at $250 \mathrm{~m}$ \\
\hline Surface emissivity $\left(\varepsilon_{s}\right)$ & $\begin{array}{l}\text { Available at } 1000 \mathrm{~m} \text { resolution from MODIS LST } \\
\text { product. But not used for disaggregation }\end{array}$ & Estimated using NDVI at $250 \mathrm{~m}$ following [30] \\
\hline Air temperature $\left(T_{a}\right)$ & $\begin{array}{l}\text { Available at } 5000 \mathrm{~m} \text { resolution from MODIS } \\
\text { atmospheric profile product. }\end{array}$ & $\begin{array}{l}\text { Assumed the same value for all the } 250 \mathrm{~m} \text { pixels } \\
\text { within a single } 5000 \mathrm{~m} \text { pixel. }\end{array}$ \\
\hline$T_{\text {Rad }}$ & $\begin{array}{l}\text { Available at } 1000 \mathrm{~m} \text { resolution from MODIS } \\
\text { LST product. }\end{array}$ & $\begin{array}{l}\text { Disaggregated to } 250 \mathrm{~m} \text { using the DisTrad } \\
\text { thermal sharpening model [17] }\end{array}$ \\
\hline Satellite overpass time ( $\left.t_{\text {pass }}\right)$ & $\begin{array}{l}\text { Available at } 1000 \mathrm{~m} \text { resolution from MODIS } \\
\text { LST product. }\end{array}$ & $\begin{array}{l}\text { Assumed the same value for all the } 250 \mathrm{~m} \text { pixels } \\
\text { within a single } 1000 \mathrm{~m} \text { pixel. }\end{array}$ \\
\hline
\end{tabular}

\subsection{In Situ Data Processing}

The estimation of $\lambda E_{\text {day }}$ from ground observation was carried out using the BREB method. Consistency checks were performed to the micrometeorological observations and any anomalous and missing data points were excluded. Air temperature and relative humidity observed at two different levels above the ground were used to estimate the Bowen ratio $(\beta)$. Observations made at $2 \mathrm{~m}$ and $4 \mathrm{~m}$ heights were used when the crop height in the catch of the tower was less than $2 \mathrm{~m}$ whereas, when the crop height was greater than $2 \mathrm{~m}$, observations made at $4 \mathrm{~m}$ and $6 \mathrm{~m}$ were used. $\beta$ was estimated every half hour and subjected to the checks prescribed by [31]. This half-hourly $\beta$ was further averaged during the entire daytime to get daytime averaged Bowen Ratio $\left(\beta_{\text {day }}\right)$ and from this, daytime averaged EF was calculated as $1 /\left(1+\beta_{\text {day }}\right)$. In this study, daytime was defined as the time during which the net shortwave radiation was positive. Using the measurements from the four component net radiometer and soil heat flux plates, $\left(R_{\mathrm{n}}-G\right)$ was estimated at half-hourly intervals and averaged over the entire daytime to get $\left(R_{\mathrm{n}}-G\right)$ day and similarly, the observations of incoming shortwave radiation were averaged over daytime to obtain $\left(R_{\mathrm{sd}}\right)_{\text {day }} . \lambda E_{\text {day }}$ was estimated by multiplying the daytime averaged EF with $\left(R_{\mathrm{n}}-G\right)_{\text {day }}$ and finally the $\lambda E_{\text {day }}$ was divided by $\left(R_{\text {sd }}\right)_{\text {day }}$ to get daytime averaged solar radiation ratio $R_{\mathrm{g}}$. These daytime averaged EF, $R_{\mathrm{g}}$ and $\lambda E_{\text {day }}$ were used to validate the satellite-based estimates. 


\section{Results and Discussion}

\subsection{Validation of Disaggregated EF and $R_{g}$ at $250 \mathrm{~m}$}

The $R_{\mathrm{g}}$-NDVI relationship that was established for the satellite data during the disaggregation of $R_{\mathrm{g}}$ was visually examined first to check for the proper determination of the minimum and maximum bounds. It was observed that $R_{\mathrm{g}}$ and NDVI exhibited an inverse triangle relationship with the minimum bound clearly increasing with NDVI. As examples, the $R_{\mathrm{g}}$-NDVI scatter observed on selected days during the rabi (winter) cropping season over Sites 3 (6 January 2011), 4 (26 January 2011), and 5 (12 December 2012) are presented in Figure 4. This kind of clear scatter was observed for over $90 \%$ of the analyzed MODIS datasets. This suggested that the $R_{\mathrm{g}}$-NDVI relation, based on which the DiSoRa model is formulated holds well.

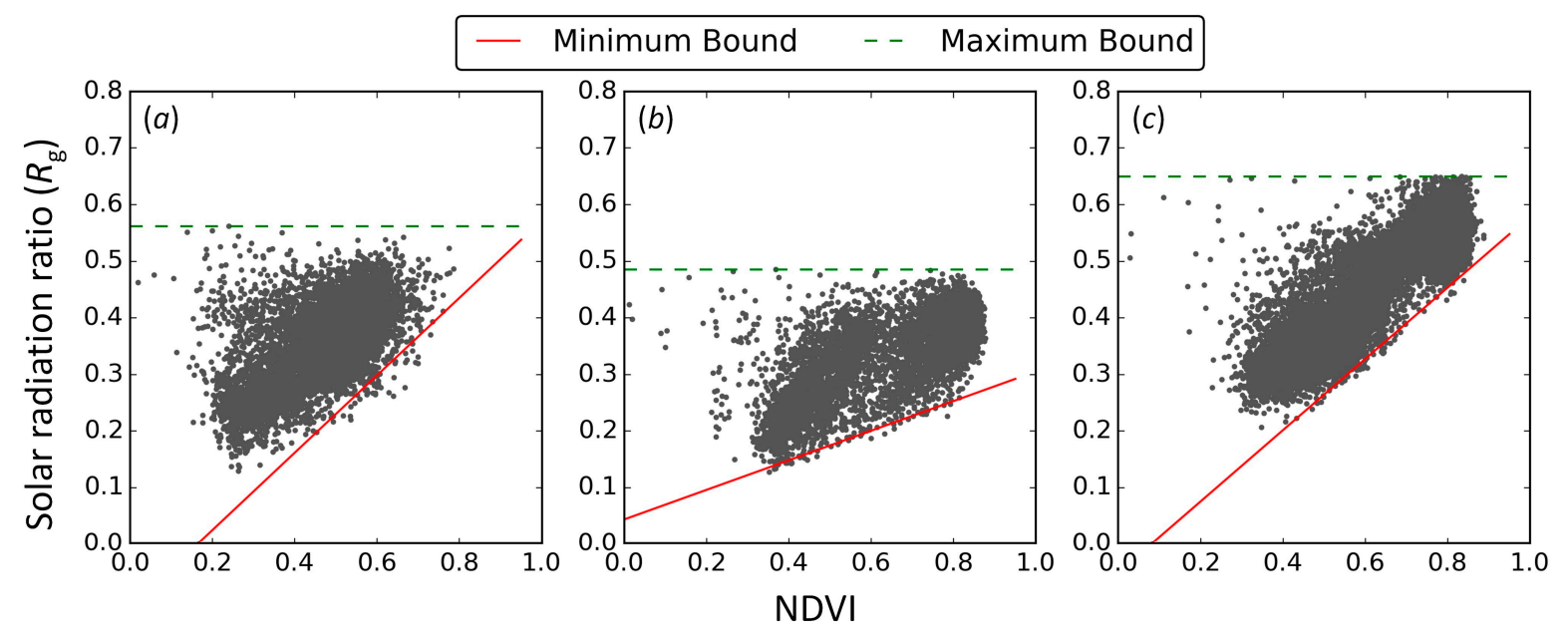

Figure 4. $R_{\mathrm{g}}$-NDVI scatter observed on selected days over (a) Site 3, (b) Site 4, and (c) Site 5.

After the visual examination, the disaggregated $R_{\mathrm{g}}$ and EF from the three approaches were validated with corresponding ground measurements. Though, the disaggregation of EF using Approaches 1 and 3 was already validated by [9] over four of the five sites in used in this study, it is revalidated here by repeating the entire exercise using additional satellite datasets and over one new site. This revalidation was to ensure the consistent performance of the DEFrac disaggregation model. Further, the DisTrad thermal sharpening model was improved from the one used in [9] by choosing NDWI for drier conditions and FVC for wetter conditions. The results of validation of disaggregated EF and $R_{\mathrm{g}}$ were analyzed in-terms of the root mean square error (RMSE), which was defined as follows:

$$
\text { RMSE }=\left[n^{-1} \sum_{i=1}^{n}(\operatorname{Modelled}[i]-\text { Observed }[i])^{2}\right]^{0.5}
$$

where, 'Modelled' denotes the satellite estimated land surface variable, 'Observed' indicates the same variable from ground observations, and $n$ is the total number of datasets used. For all the five sites taken together, the RMSE in the satellite estimated $R_{\mathrm{g}}$ at $1000 \mathrm{~m}$ and $250 \mathrm{~m}$ (disaggregated using the DiSoRa model) resolutions was estimated to be 0.07 (17\% of the mean observed $\left.R_{\mathrm{g}}\right)$ and $0.06(15 \%$ of the mean observed $R_{\mathrm{g}}$ ), respectively. The coefficient of determination $\left(R^{2}\right)$ also marginally improved from 0.82 to 0.83 for $R_{\mathrm{g}}$ after disaggregation. In the case of disaggregated EF, the RMSE was $0.10(16 \%$ of the mean observed EF) for both EF at $1000 \mathrm{~m}\left(R^{2}=0.75\right)$ and $250 \mathrm{~m}\left(R^{2}=0.76\right)$ resolutions when the disaggregation was carried out using the DEFrac model (Approach 1). However, when Approach 3 was used for disaggregating the EF, the RMSE increased to 0.17 (28\% of the mean observed EF) and $R^{2}$ decreased to 0.32 . The comparison between EF and $R_{\mathrm{g}}$ estimated from ground measurements and the satellite data is presented in Figure 5 and the site-wise error values are listed in Table 2. 
(a) Approach 1

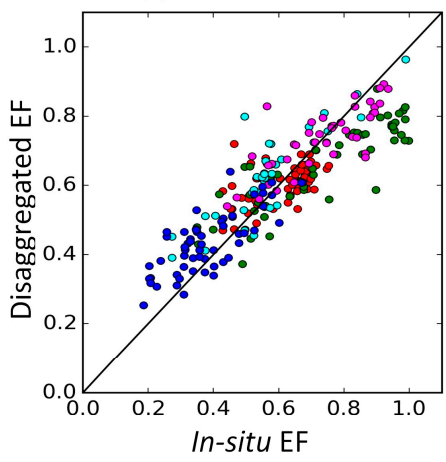

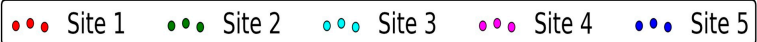
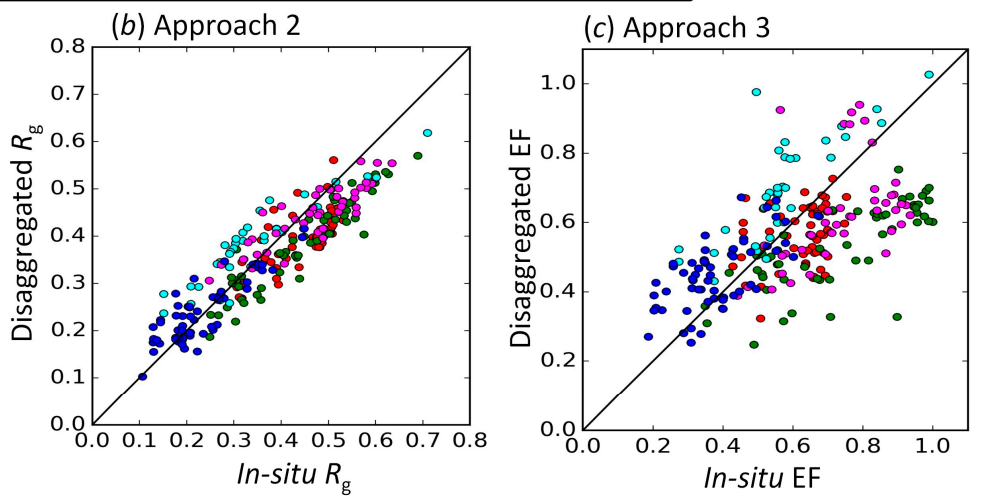

Figure 5. Comparison between ground observed and disaggregated (a) EF using the DEFrac model, (b) $R_{\mathrm{g}}$ using the DiSoRa model, and (c) EF using the DisTrad thermal sharpening model over the five sites.

Table 2. Results of comparison between ground observations, disaggregated $\mathrm{EF}$, and disaggregated $R_{\mathrm{g}}$.

\begin{tabular}{cccccc}
\hline \multirow{2}{*}{ Site } & \multicolumn{5}{c}{ RMSE } \\
\cline { 2 - 6 } & EF 1000 $\mathbf{~ E F ~ 2 5 0 ~} \mathbf{~ m ~ D E F r a c ~}$ & EF 250 m DisTrad & $\boldsymbol{R}_{\mathbf{g}} \mathbf{1 0 0 0} \mathbf{~ m}$ & $\boldsymbol{R}_{\mathbf{g}} \mathbf{2 5 0} \mathbf{~ m ~ D i S o R a ~}$ \\
\hline Site 1 & 0.08 & 0.08 & 0.11 & 0.08 & 0.07 \\
Site 2 & 0.14 & 0.13 & 0.24 & 0.08 & 0.07 \\
Site 3 & 0.09 & 0.09 & 0.16 & 0.07 & 0.07 \\
Site 4 & 0.08 & 0.08 & 0.18 & 0.05 & 0.05 \\
Site 5 & 0.09 & 0.09 & 0.11 & 0.04 & 0.04 \\
\hline
\end{tabular}

From Table 2, it can be observed that the disaggregation of EF using the DisTrad thermal sharpening model resulted in higher errors than the EF at $1000 \mathrm{~m}$ resolution. On the other hand, the disaggregation of EF and $R_{\mathrm{g}}$ using the DEFrac and the DiSoRa models, respectively, resulted in marginal improvements in RMSE (which is not seen in Table 2 due to rounding off) at all the five sites. The RMSE in both the disaggregated EF and $R_{\mathrm{g}}$ was within $15 \%$ of the mean ground observed values at all but one site (Site 2), where, the error was within $20 \%$ of the mean observed value. A relatively higher RMSE in EF was observed at Site 2 due to the mismatch between the landcover conditions of the catch of the flux tower and the MODIS satellite pixel [13]. The disaggregation using the DisTrad thermal sharpening model (Approach 3) has introduced more errors in the EF estimated using the triangle model. A similar result was obtained in an earlier study [9] where it was mentioned that the relative positions of $T_{\text {Rad }}$ pixels gets modified in the $T_{\text {Rad }}$-NDVI context space when disaggregated thermal data is used in the triangle model. Though the DisTrad model was improved by choosing a suitable vegetation index, the disaggregated $T_{\text {Rad }}$ was not accurate enough to be used in the contextual models such as the triangle model for the estimation of disaggregated EF.

\subsection{Validation of Disaggregated $\lambda E_{\text {day }}$ at $250 \mathrm{~m}$}

The disaggregated EF and $R_{\mathrm{g}}$ were converted into $\lambda E_{\text {day }}$, which was compared against ground observations. For all five sites considered together, the RMSE in the $1000 \mathrm{~m} \lambda E_{\text {day }}$ was found to be $34 \mathrm{~W} \mathrm{~m}^{-2}$. Similarly, the RMSE of the disaggregated $\lambda E_{\text {day }}$ was $32 \mathrm{~W} \mathrm{~m}^{-2}, 30 \mathrm{~W} \mathrm{~m}^{-2}$, and $48 \mathrm{~W} \mathrm{~m}^{-2}$ for Approaches 1, 2, and 3, respectively. The $R^{2}$ was determined to be $0.69,0.71$, and 0.37 for the three approaches taken in order, respectively. The RMSE values for individual sites are presented in Table 3. 
Table 3. Results of the comparison between ground observations and satellite-obtained $\lambda E_{\text {day }}$.

\begin{tabular}{|c|c|c|c|c|}
\hline \multirow{2}{*}{ Site } & \multirow{2}{*}{ RMSE for $\lambda E_{\text {day }} 1000 \mathrm{~m}\left(\mathrm{~W} \mathrm{~m}^{-2}\right)$} & \multicolumn{3}{|c|}{ RMSE for $\lambda E_{\text {day }}$ at $250 \mathrm{~m}\left(\mathrm{~W} \mathrm{~m}^{-2}\right)$} \\
\hline & & Approach 1 & Approach 2 & Approach 3 \\
\hline Site 1 & 33 & 31 & 31 & 40 \\
\hline Site 2 & 39 & 38 & 36 & 62 \\
\hline Site 3 & 44 & 40 & 40 & 58 \\
\hline Site 4 & 30 & 27 & 25 & 47 \\
\hline Site 5 & 25 & 25 & 25 & 31 \\
\hline
\end{tabular}

From Table 3, it can be observed that the disaggregation of $\lambda E_{\text {day }}$ to $250 \mathrm{~m}$ using Approaches 1 and 2 has marginally improved the RMSE at all five sites in comparison to $\lambda E_{\text {day }}$ at $1000 \mathrm{~m}$, and the performance of the first two approaches were similar at all five sites. However, disaggregation using Approach 3 had resulted in higher errors than $1000 \mathrm{~m}$ at all sites. Further analyses revealed that the RMSE in the satellite-estimated $\left(R_{\mathrm{n}}-G\right)_{\text {day }}$ was estimated to be $29 \mathrm{~W} \mathrm{~m}^{-2}$ and $27 \mathrm{~W} \mathrm{~m}^{-2}$ at $1000 \mathrm{~m}$ and $250 \mathrm{~m}$ resolutions, respectively, for all five sites considered together. This shows that the higher error in disaggregated $\lambda E_{\text {day }}$ using Approach 3 was predominantly due to the error in the disaggregation of EF rather than disaggregation of $\left(R_{\mathrm{n}}-G\right)_{\text {day }}$.

The spatial patterns of the $\lambda E_{\text {day }}$ observed over Site 5 on a selected day (14 November 2012) in the rabi (winter) cropping season at $1000 \mathrm{~m}$ and $250 \mathrm{~m}$ is presented in Figure 6. From the Figure, it can be observed that spatial disaggregation to $250 \mathrm{~m}$ using Approaches 1 (Figure 6b) and 2 (Figure 6c) had improved the detail of the $\lambda E_{\text {day }}$ image at $1000 \mathrm{~m}$ (Figure 6a) and at the same time preserved the spatial pattern observed in the $1000 \mathrm{~m}$ image. On the other hand, disaggregation using Approach 3 (Figure 6d) under-predicted $\lambda E_{\text {day }}$ values especially in the west-southwest parts of the spatial grid.
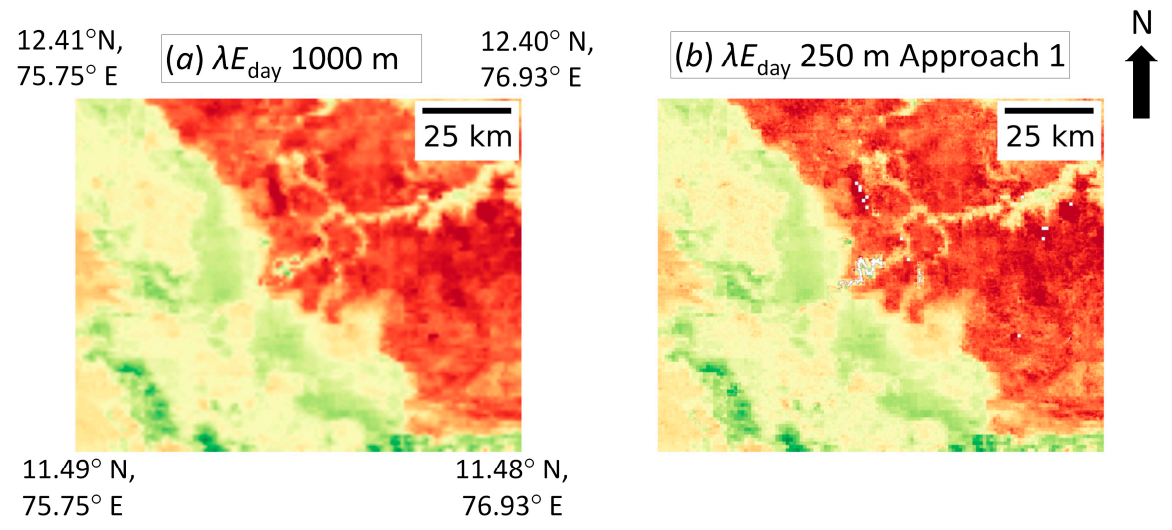

(c) $\lambda E_{\text {day }} 250 \mathrm{~m}$ Approach 2

(d) $\lambda E_{\text {day }} 250 \mathrm{~m}$ Approach 3

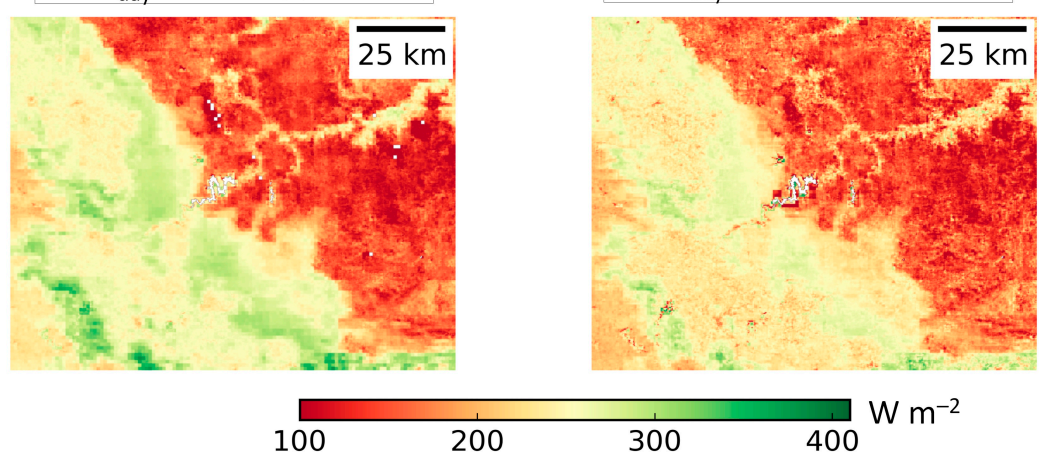

Figure 6. Spatial pattern of $\lambda E_{\text {day }}$ observed on 14 November 2012 over Site 5. (a) $\lambda E_{\text {day }}$ at $1000 \mathrm{~m}$ resolution and (b-d) $\lambda E_{\text {day }}$ disaggregated to $250 \mathrm{~m}$ using approaches 1,2 and 3 respectively. 
These results suggest that both Approaches 1 and 2 can be used for spatial disaggregation of $\lambda E_{\text {day }}$. However, it can also be observed that the disaggregation using the DiSoRa model (i.e., Approach 2) is relatively simpler and has fewer steps than disaggregation using the other two approaches. Especially, the additional disaggregation of $T_{\text {Rad }}$ to estimate $\left(R_{\mathrm{n}}-G\right)$ can be avoided if disaggregation based on $R_{\mathrm{g}}$ (DiSoRa model) is carried out. Furthermore, the results from the $R_{\mathrm{g}}$-based disaggregation can be improved by either calibrating Equation (4) to the specific region of interest, or using other reliable data/models to obtain $R_{\mathrm{sd}}$ instead of using the empirical equation.

The major limitation of the proposed disaggregation Approaches 1 and 2 is the accuracy of the disaggregated $\lambda E_{\text {day }}$ is limited by the accuracy of $\mathrm{EF} / R_{\mathrm{g}}$ at $1000 \mathrm{~m}$ resolution. Hence, it becomes necessary to test a model for estimation of $\lambda E_{\text {day }}$ at coarse spatial resolution over the region of interest and then use this disaggregation approach. For example, the EF and radiation models used in this study were chosen after comparison with other models over all the five sites [13]. Further, in this study, data from only one Bowen ratio tower was available in each of five spatial grids. Ideally, data from multiple spatially-distributed towers within each grid would be required for performing a robust validation of the disaggregation approaches. This was not possible now as there are only a handful of flux towers available across India. However, with increasing number of hydrological observatories in India, in the near future, it should be possible to validate these approaches with data from multiple flux towers within a given spatial grid or river watershed.

\section{Conclusions}

This paper compared three simple approaches for the disaggregation of latent heat flux $(\lambda E)$. The first two approaches are, respectively, based on the disaggregation of the evaporative fraction (EF, DEFrac model) and the solar radiation ratio $\left(R_{\mathrm{g}}\right.$, DiSoRa model), and the third approach is based on disaggregation of thermal data $\left(T_{\mathrm{Rad}}\right)$ for estimation of finer resolution latent heat flux. The three approaches were tested using MODIS datasets over five sites in India and the validation was carried out using data from Bowen Ratio energy balance (BREB) micrometeorological towers. The validation suggested that utilizing the disaggregated $T_{\mathrm{Rad}}$ for the estimation of disaggregated $\lambda E$ (RMSE $=48 \mathrm{~W}$ $\mathrm{m}^{-2}$ ) resulted in larger errors than the original estimates at $1000 \mathrm{~m}\left(\mathrm{RMSE}=34 \mathrm{~W} \mathrm{~m}^{-2}\right)$. The results further revealed that the higher error in disaggregated $\lambda E$ from this approach is due to errors in the disaggregated EF rather than the errors in disaggregated $\left(R_{n}-G\right)$. In this study, the triangle model was used for the estimation of EF, and the accuracy of the estimated EF from the triangle model is sensitive to the relative position of $T_{\text {Rad }}$ of a pixel with respect to the wet and the dry edges in the $T_{\text {Rad }}$-NDVI context space. Using the disaggregated $T_{\text {Rad }}$ in the triangle model had perturbed this relative position of pixels in the $T_{\text {Rad }}$-NDVI context space resulting in higher errors.

The approaches based on the disaggregation of $\mathrm{EF}$ and $R_{\mathrm{g}}$ produced equally better results at all five sites, and marginally improved the error values of the disaggregated $\lambda E$ in comparison with $1000 \mathrm{~m}$ estimates. The RMSE of the disaggregated $\lambda E$ was $32 \mathrm{~W} \mathrm{~m}^{-2}$ and $30 \mathrm{~W} \mathrm{~m}^{-2}$, respectively, for EF and $R_{\mathrm{g}}$-based disaggregation. Both these approaches have performed in a similar manner as they share the same physical basis. However, by converting EF into $R_{\mathrm{g}}$, the need to estimate $\left(R_{\mathrm{n}}-G\right)$ at finer spatial resolution is avoided, thereby making Approach 2 simpler with fewer data processing steps. Future studies should focus on utilizing the DiSoRa and the DEFrac models for the disaggregation of $\lambda E$ estimated from models like the SEBAL, two source model, etc. and re-validating these approaches at multiple sites across the globe.

Acknowledgments: The first author acknowledges the INSPIRE (IF 110547) fellowship provided by Department of Science and Technology, Government of India for his doctoral studies. This publication was supported by the grants from the Ministry of Earth Sciences, Government of India and the National Environment Research Council, United Kingdom through the UPSCAPE and the INCOMPASS projects.

Author Contributions: Eswar and Sekhar conceived the work. Eswar processed the data and interpreted the results with inputs from Sekhar. Bhattacharya and Bandyopadhyay provided expertise in ground data collection and processing. 
Conflicts of Interest: The authors declare no conflict of interest.

\section{References}

1. Bastiaanssen, W.G.M.; Menenti, M.; Feddes, R.A.; Holstlag, A.A.M. A remote sensing surface energy balance algorithm for land (SEBAL). 1: Formulation. J. Hydrol. 1998, 213, 198-212. [CrossRef]

2. Allen, R.G.; Tasumi, M.; Trezza, R. Satellite-Based Energy Balance for Mapping Evapotranspiration with Internalized Calibration (METRIC)—Model. J. Irrig. Drain. Eng. 2007, 133, 380-394. [CrossRef]

3. Allen, R.G.; Morse, A.; Tasumi, M.; Trezza, R.; Bastiaanssen, W.; Wright, J.L.; Kramer, W. Evapotranspiration from a Satellite-Based Surface Energy Balance for the Snake Plain Aquifer in Idaho. California Water Plan 2005, 4, 161-175.

4. Anderson, M.C.; Allen, R.G.; Morse, A.; Kustas, W.P. Use of Landsat thermal imagery in monitoring evapotranspiration and managing water resources. Remote Sens. Environ. 2012, 122, 50-65. [CrossRef]

5. Kustas, W.P.; Norman, J.M.; Anderson, M.C.; French, A.N. Estimating subpixel surface temperatures and energy fluxes from the vegetation index-radiometric temperature relationship. Remote Sens. Environ. 2003, 85, 429-440. [CrossRef]

6. Agam, N.; Kustas, W.P.; Anderson, M.C.; Li, F.; Neale, C.M.U. A vegetation index based technique for spatial sharpening of thermal imagery. Remote Sens. Environ. 2007, 107, 545-558. [CrossRef]

7. Agam, N.; Kustas, W.P.; Anderson, M.C.; Li, F.; Colaizzi, P.D. Utility of thermal image sharpening for monitoring field-scale evapotranspiration over rainfed and irrigated agricultural regions. Geophys. Res. Lett. 2008, 35, L02402. [CrossRef]

8. Bindhu, V.M.; Narasimhan, B.; Sudheer, K.P. Development and verification of a non-linear disaggregation method (NL-DisTrad) to downscale MODIS land surface temperature to the spatial scale of Landsat thermal data to estimate evapotranspiration. Remote Sens. Environ. 2013, 135, 118-129. [CrossRef]

9. Eswar, R.; Sekhar, M.; Bhattacharya, B.K. A simple model for spatial disaggregation of evaporative fraction: Comparative study with thermal sharpened land surface temperature data over India. J. Geophys. Res. Atmos. 2013, 118, 12,029-12,044. [CrossRef]

10. Hong, S.H.; Hendrickx, J.M.H.; Borchers, B. Down-scaling of SEBAL derived evapotranspiration maps from MODIS (250 m) to Landsat (30 m) scales. Int. J. Remote Sens. 2011, 32, 6457-6477. [CrossRef]

11. Mallick, K.; Bhattacharya, B.K.; Rao, V.; Reddy, D.R.; Banerjee, S.; Venkatesh, H.; Pandey, V.; Kar, G.; Mukherjee, J.; Vyas, S.P.; et al. Latent heat flux estimation in clear sky days over Indian agroecosystems using noon-time satellite remote sensing data. Agric. For. Meteorol. 2009, 149, 1646-1665. [CrossRef]

12. Bhattacharya, B.K.; Mallick, K.; Patel, N.K.; Parihar, J.S. Regional clear sky evapotranspiration over agricultural land using remote sensing data from Indian geostationary meteorological satellite. J. Hydrol. 2010, 387, 65-80. [CrossRef]

13. Eswar, R.; Sekhar, M.; Bhattacharya, B.K. Comparison of three remote sensing based models for the estimation of latent heat flux over India. Hydrol. Sci. 2017. accepted.

14. Cammalleri, C.; Anderson, M.C.; Kustas, W.P. Upscaling of evapotranspiration fluxes from instantaneous to daytime scales for thermal remote sensing applications. Hydrol. Earth Syst. Sci. 2014, 18, 1885-1894. [CrossRef]

15. Tang, R.; Li, Z.L.; Sun, X. Temporal upscaling of instantaneous evapotranspiration: An intercomparison of four methods using eddy covariance measurements and MODIS data. Remote Sens. Environ. 2013, 138, 102-118. [CrossRef]

16. Van Niel, T.G.; McVicar, T.R.; Roderick, M.L.; van Dijk, A.I.J.M.; Beringer, J.; Hutley, L.B.; van Gorsel, E. Upscaling latent heat flux for thermal remote sensing studies: Comparison of alternative approaches and correction of bias. J. Hydrol. 2012, 468-469, 35-46. [CrossRef]

17. Eswar, R.; Sekhar, M.; Bhattacharya, B.K. Disaggregation of LST over India: Comparative analysis of different vegetation indices. Int. J. Remote Sens. 2016, 37, 1035-1054. [CrossRef]

18. Jiang, L.; Islam, S. A methodology for estimation of surface evapotranspiration over large areas using remote sensing observations. Geophys. Res. Lett. 1999, 26, 2773-2776. [CrossRef]

19. Venturini, V.; Bisht, G.; Islam, S.; Jiang, L. Comparison of evaporative fractions estimated from AVHRR and MODIS sensors over South Florida. Remote Sens. Environ. 2004, 93, 77-86. [CrossRef] 
20. Batra, N.; Islam, S.; Venturini, V.; Bisht, G.; Jiang, L. Estimation and comparison of evapotranspiration from MODIS and AVHRR sensors for clear sky days over the Southern Great Plains. Remote Sens. Environ. 2006, 103, 1-15. [CrossRef]

21. Tang, R.; Li, Z.L.; Tang, B. An application of the Ts-VI triangle method with enhanced edges determination for evapotranspiration estimation from MODIS data in arid and semi-arid regions: Implementation and validation. Remote Sens. Environ. 2010, 114, 540-551. [CrossRef]

22. Tang, R.; Li, Z.L.; Chen, K.S. Validating MODIS-Derived land surface evapotranspiration with in situ measurements at two AmeriFlux sites in a semiarid region. J. Geophys. Res. Atmos. 2011, 116, D04106. [CrossRef]

23. Laxmi, K.; Nandagiri, L. Latent heat flux estimation using trapezoidal relationship between MODIS land surface temperature and fraction of vegetation-application and validation in a humid tropical region. Remote Sens. Lett. 2014, 5, 981-990. [CrossRef]

24. Martínez Pérez, J.Á.; García-Galiano, S.G.; Martin-Gorriz, B.; Baille, A. Satellite-Based Method for Estimating the Spatial Distribution of Crop Evapotranspiration: Sensitivity to the Priestley-Taylor Coefficient. Remote Sens. 2017, 9, 611. [CrossRef]

25. Petropoulos, G.; Carlson, T.N.; Wooster, M.J.; Islam, S. A review of Ts/VI remote sensing based methods for the retrieval of land surface energy fluxes and soil surface moisture. Prog. Phys. Geogr. 2009, 33, 224-250. [CrossRef]

26. Liang, S. Narrowband to broadband conversions of land surface albedo: I. Algorithms. Remote Sens. Environ. 2000, 76, 213-238. [CrossRef]

27. Jin, M.; Liang, S. An Improved Land Surface Emissivity Parameter for Land Surface Models Using Global Remote Sensing Observations. J. Clim. 2006, 19, 2867-2881. [CrossRef]

28. Campbell, G.S.; Norman, J.M. An Introduction to Environmental Biophysics, 2nd ed.; Springer: New York, NY, USA, 1998; p. 164.

29. Bisht, G.; Venturini, V.; Islam, S.; Jiang, L. Estimation of net radiation using MODIS (Moderate Resolution Imaging Spectroradiometer) data for clear sky days. Remote Sens. Environ. 2005, 97, 52-67. [CrossRef]

30. Valor, E.; Caselles, V. Mapping land surface emissivity from NDVI: application to European, African and South American areas. Remote Sens. Environ. 1996, 57, 167-184. [CrossRef]

31. Perez, P.J.; Castellvi, F.; Ibanez, M.; Rosell, J.I. Assessment of reliability of Bowen ratio method for partitioning fluxes. Agric. For. Meteorol. 1999, 97, 141-150. [CrossRef] 